\title{
Competition Between Firms that Bundle
}

\section{Information Goods}

\author{
Scott A. Fay * Jeffrey K. MacKie-Mason ${ }^{\dagger}$ \\ July $2001^{\ddagger}$
}

\begin{abstract}
Information goods, such as journal articles, require substantial initial investment, but low incremental reproduction and distribution costs. Advances in computing and digital communications have nearly eliminated these incremental costs. Thus, positive per-item prices are inefficient because they discourage consumption with value greater than marginal cost. Further, very low per item prices will not recover first-copy costs and thus firms will not have an incentive to create new content. Bundling may be desirable in such a market: individuals pay no marginal fee for each item consumed and the producer is able to recover investment expenses through the bundled sales.
\end{abstract}

*Warrington College of Business, University of Florida, Gainesville, FL 32611, faysa@notes.cba.ufl.edu.

${ }^{\dagger}$ Department of Economics and School of Information, University of Michigan, Ann Arbor, MI 48109, jmm@umich.edu.

${ }^{\ddagger}$ We appreciate helpful comments from Kai-Uwe Kuhn, audiences at the Federal Trade Commission, the University of California at Berkeley, the University of Florida, the University of Michigan, and the Telecommunications Policy Research Conference. We gratefully acknowledge support from NSF grant SBR-9230481 and two University Partnership grants from IBM. 
Most previous research on bundling assumes a monopoly seller and stochastically identical consumers. In this paper we analyze the profitability and welfare properties of bundling information goods in a multi-firm setting. We also introduce a feasible but flexible specification for heterogeneous consumer preferences. Modeling heterogeneity resolves unrealistic predictions about efficiency and distribution from the prior literature. Introducing competition from a second firm selling imperfect substitutes results in much lower prices yet only a moderate profit reduction. Bundling leads to particularly fierce competition since consumers either buy all of a firm's collection or nothing. As a result, competition weakens, and sometimes reverses, the strong advantage known for monopoly bundling. We find that although lower profit under competition reduces the incentive to create new content, the distributional efficiency gains in this differentiated product market typically outweigh the welfare cost of reduced creation.

\section{Introduction}

Computing and digital communications costs have both decreased at the remarkable rate of about 30\% per year since the early 1960s (MacKie-Mason and Varian 1996). Such a revolutionary shift in information technology costs is enabling revolutions in product configuration and pricing structures. For example, it is not economically feasible for the New York Times to sell articles individually when it is necessary to print articles separately and physically deliver them to customers through the postal system. However, when all articles are available on a Web site, it becomes feasible for consumers to download and pay for only those articles they desire to read, which indeed is the model implemented by the New York Times for its archives. 
Information goods are characterized by high fixed (first-copy) costs, but low costs for the production of additional copies. This cost structure characterizes print-onpaper publishing too, but is greatly exaggerated in electronic publishing. Standard linear pricing for electronic information goods cannot result in efficient production or distribution because pricing at (near-zero) marginal cost would not recover the initial fixed costs. The flexibility of digital technology also permits a wider range of responses to the cost problem. Consequently, there is great uncertainty about how markets for electronic publishing will evolve. For example, in the industry of scholarly publishing, University presidents and librarians are expressing alarm that the introduction of electronic publication and distribution seems to be increasing prices for scholarly journals (Gilpin 1997). We offer some insight into how the interaction between new technologies and the competitive environment is likely to affect readers, authors and publishers.

Several authors have recently studied a monopolist that sells information goods as a bundle (Bakos and Brynjolfsson 1998, Chuang and Sirbu 1998, MacKie-Mason and Riveros 1998). When consumers have approximately the same average valuation for items in a bundle, monopoly bundling can generate more revenue than per-item selling by capturing the common average value while smoothing out idiosyncratic preferences. In addition, if per transaction costs are significant monopoly bundling may be profitable. In this paper we study the use of bundling when firms compete in the selling of information goods. Thus, we address the interaction between market structure and bundled pricing strategies.

We address several questions. How much does competition curb the ability of bundling firms to extract value from consumers? What is the net effect of information goods bundling on social welfare, taking into account both consumers' surplus and 
profits? What are the dynamic implications of bundling for the surplus necessary to induce investment in the new creation of information goods?

We study a specific problem, but one with broad relevance given recent advances in digital information production and electronic distribution. Two firms each produce multiple imperfect substitutes (consistent with copyright and reputation effects, the latter important for experience goods such as information products). They consider bundling, component pricing, and mixed bundling. There may be substantial sunk costs to create the goods, but the marginal cost of reproducing and distributing the goods is zero. An important contribution of our work, for the analysis of both monopoly and competitive bundling, is that we study both consumers stochastically identical in their average valuation of the bundled goods (consistent with much of the prior literature) and consumers with heterogeneous preferences.

As previous research has shown for a monopoly, bundling is usually more profitable than selling items separately. However, with more than one firm, bundling also results in rather fierce competition. Thus the distribution of surplus between firm and consumer is quite different than for a monopoly. We find that a duopoly serving a diverse population of consumers is drastically more efficient than a monopoly. A duopoly will result in much lower prices for the consumers, much higher social welfare, and only a moderate reduction in firms' profits.

Our results when consumers' preferences are ex ante heterogeneous reinforce the effectiveness of competition from even one firm. Prices are much lower and social welfare higher than for a monopoly. We are also able to offer new insight into two issues raised by the prior literature. The standard results for stochastically identical consumers have been that a bundling monopolist achieves the first best allocation and simultaneously extracts $100 \%$ of consumers' surplus. Neither of these results seem 
to describe many information markets. Our model of a market with heterogeneous preferences provides one possible explanation for what we observe in actual markets. In our model, bundling is not generally fully efficient, and sometimes is even less efficient than per item selling. In addition, consumers retain a significant share of total surplus.

Our results on the effect of competition on static efficiency and surplus distribution raise questions about the dynamic efficiency of a competitive information goods market. Lower profit reduces the incentive to invest in information product creation. With stochastically identical consumers we find that the received profit leads to just the right amount of new creation. With heterogeneous consumers neither a monopoly nor a duopoly have efficient incentives to create new content. In our model, monopoly creation is closer to the social optimum. However, the duopoly is usually socially preferred because its lower prices result in sufficiently greater distribution of new content to outweigh the smaller creation effort.

In Section 2 we provide a brief review of prior research. We introduce a general model of consumer demand and present analytical results for stochastically identical consumers in Section 3. In Section 4 we employ numerical methods to analyze competitive bundling when consumer preferences are meaningfully heterogeneous. In Section 5, we allow firms to endogenously determine how much to invest in new content. Finally, we offer some concluding remarks in Section 6 .

\section{Prior Research}

In their seminal paper on bundling Adams and Yellen (1976) consider a monopolist producing two goods. They analyze three pricing strategies: component selling 
(each good priced and sold individually), bundling (both goods sold together) and mixed bundling (consumers offered choice between buying a bundle or individual components). They show by example that bundling can result in higher revenue than component selling. However, bundling might result in inefficient consumption of components for which the marginal cost of producing that component exceeds its value to a consumer. In order to obtain, say, the highly valued good 1, a consumer might purchase the bundle and thus consume good 2 even if its marginal value is less than its marginal cost. McAfee, McMillan, and Whinston (1989) extend the analysis to general demand functions, and provide conditions under which mixed bundling strictly dominates either of the two pure strategies. ${ }^{1}$ Salinger (1995) shows that if valuations for the two goods are not perfectly correlated, the demand for the bundle will be more price-elastic than the sum of the individual demands for each component. As a result, bundling is a way to smooth out idiosyncratic preferences enabling a monopolist to extract more consumers' surplus than is possible through pure components pricing.

Some recent papers have extended the analysis to more than two goods. In principle, with $N$ goods, there are $2^{N}-1$ combinations or bundles that could be offered, each at a potentially unique price, and consumer preferences would need to be specified on this $2^{N}-1$-dimensional space. Even ignoring consumer information processing and transactions costs from dealing with an exponentially-large price list, the profit maximization problem for setting those prices is NP-hard and generally considered to be computationally intractable for modern computers when $N$ is only moderately large. ${ }^{2}$ As a result, nearly all of these papers restrict attention to the same three

\footnotetext{
${ }^{1}$ Mixed bundling must perform at least as well as either pure bundling or pure unbundling since it contains both pure strategies as sub-cases.

${ }^{2}$ For an exponentially complex problem, doubling the speed of the computer only allows us to increase the size of the problem by one. For a single scholarly publisher, $N$ might be several thousand
} 
strategies: components pricing, bundling, and mixed bundling. ${ }^{3}{ }^{4}$ We follow the same approach in this paper.

Bakos and Brynjolfsson (1998) illustrate that bundling with $\mathrm{N}$ goods is strictly preferred to components pricing when marginal cost is zero, consumers are stochastically identical (each draws values for an item from the same distribution), and $\mathrm{N}$ is sufficiently large. Chuang and Sirbu (1998) allow for the possibility of mixed bundling and not surprisingly find that it is more profitable than either of the pure strategies. They also allow readers to value some articles at less than marginal production cost. Thus it is possible for component selling to strictly dominate bundling since bundling results in the costly distribution of products that have below-cost value to some consumers.

Little research has been done on the possibility of bundling when there is more than one firm. Fishburn, Odlyzko, and Siders (2000) consider a duopoly in which each firm produces an identical set of $N$ information goods (perfect substitutes). By assumption, one firm bundles while the other offers component pricing. In nearly all of their numerical simulations, a price war ensues with both firms' prices falling towards zero (marginal cost). This situation, although nearing static efficiency, erodes the incentive to create new content.

Matutes and Regibeau (1992) and Farrell, Monroe, and Saloner (1998) consider duopolists that produce complements rather than substitutes. In their work, both articles per year; Elsevier Science publishes several hundred thousand.

${ }^{3}$ In one exception, Hanson and Martin (1990) tackle the full $2^{N}$ bundle pricing problem with $N$ $=21$.

${ }^{4}$ MacKie-Mason and Riveros (1998) introduce a new alternative: generalized subscriptions. Consumers prepay for $G$ tokens, then select $G$ items from the entire collection after the items are created. In effect, individual-specific sub-bundles are created. Riveros (1999) comparatively evaluates generalized subscriptions against the three most studied strategies. 
goods must be purchased to form a system, though it might be possible to purchase the components from separate firms. ${ }^{5}$ In our work we consider imperfect substitutes and consumers can vary the number of different articles that they consume. Some authors examine bundling as a tying strategy when one firm is a monopolist over one product but faces potential competition for a second product (see, e.g., Carbajo, Meza, and Seidmann 1990, Whinston 1990, and Aron and Wildman 1999). ${ }^{6}$ We assume that there is (imperfect) competition over all goods.

Bakos and Brynjolfsson (1999) is most closely related to our research. They also consider a duopoly in an $N$-good market. However, two main characteristics differentiate our approaches. First, they only consider consumers who are (stochastically) identical. We obtain results for a market in which consumers have heterogeneous preferences. The assumption of stochastically identical (i.e., ex ante homogeneous) preferences is quite restrictive: for example, it implies that a monopolist will maximize social welfare but will extract all available consumers' surplus. Second, they only consider goods that are pair-wise substitutes: the demand for one good is independent of the demand for all but one of the remaining goods. This drastically restricts the possible strategic interactions. In our model one firm's bundle of information items is an imperfect substitute for all of the items offered by the second firm, and thus depresses their value. Consequently, we find quite different equilibrium prices, and a quite different distribution of surplus.

\footnotetext{
${ }^{5}$ Nalebuff (2000) finds that a firm that sells a bundle of complementary products will have a substantial advantage over rivals who sell the component products individually.

${ }^{6}$ Nalebuff (1999) explores how bundling can be used as an entry deterrent.
} 


\section{Stochastically identical Consumers}

In this section we analyze the market when consumers are ex ante stochastically identical. By "ex ante" we refer to their preferences in terms of stochastic value distributions, before the realized value of each item is revealed to each consumer. We assume that firms cannot distinguish between buyers except through how many items they purchase. Therefore, there is no opportunity for third-degree price discrimination, and pricing can usefully vary only by the number of items purchased (second-degree discrimination). Further, we assume that the distributions of consumer values for each individual item are ex ante identical, so there is no advantage to charging different prices for different items. Since we assume zero marginal costs of reproduction and distribution, firms do not put any restriction on which items a consumer may buy; that is, price functions take the form $P(n)$, which is the price charged for any $n$ items a consumer wishes to obtain.

We now turn to ex ante consumer valuations of a bundle of the consumer's $n$ most preferred items. Our assumption of ex ante identical consumer value distributions for each item implies that the ex ante value function for a consumer's $n$ most preferred items is the same for all consumers. ${ }^{7}$ Thus, stochastically identical ex ante item preferences imply the same stochastic homogeneity in $n$-item bundle preferences. Formally, $V_{j}(n)=V(n)$ for all customers $j$, where $V_{j}(n)$ is the gross value to consumer $j$ of consuming its $n$ most preferred items. With this specification, individuals can differ in their rank orderings of items, as long as they value their $n$ most preferred the same as each other for all $n \geq 0$.

We analyze this market as a duopoly game in which the two firms simultaneously choose whether to bundle, and what price schedule to set. We assume two firms,

\footnotetext{
${ }^{7}$ Equivalently, one can think of this specification as a primitive on ex ante $n$-item preferences.
} 
which control disjoint item collections of size $N_{1}$ and $N_{2}$, respectively. Each can either bundle and sell all $N_{i}$ items for a single price of $P_{i}$, or sell individual items at a unit price of $p_{i}$. To solve the simultaneous game, we first solve for the pure strategy price equilibrium in each of three possible cases: both firms bundle; neither bundles; or only one bundles. We then consider how the bundling decision is made and find that in this game with simultaneous pricing and bundling choice, both firms' best strategy is to bundle. In the final subsection we make endogenous the choice of bundle size, and obtain a surprising result on the efficiency of the outcome.

\subsection{Demand}

Two firms each control a collection of items, size $N_{1}$ and $N_{2}$ respectively. We label the items from each firm's collection so that $n_{i}^{j}$ represents the item that is the $j$ th consumer's $n$th most preferred item from firm $i$. Let $V\left(n_{1}^{j}, n_{2}^{j}\right)$ be consumer $j$ 's ex ante gross value of consuming her $n_{1}$ most preferred items from collection 1 and $n_{2}$ most preferred items from collection 2.8 Consumers are stochastically identical so that $V\left(n_{1}^{j}, n_{2}^{j}\right)=V\left(n_{1}, n_{2}\right)$ for all $j$. Thus if consumers knew the value of each item before purchase, and could select which items to purchase, they would demand the same number of items given any price function, but the set of items each demands may be different. We normalize the number of consumers to one. We assume $V\left(n_{1}, n_{2}\right)$ is concave:

$$
\begin{array}{cl}
\frac{\partial V\left(n_{1}, n_{2}\right)}{\partial n_{i}} \geq 0 & i=1,2 \\
\frac{\partial^{2} V\left(n_{1}, n_{2}\right)}{\partial n_{i}^{2}} \leq 0 & i=1,2 .
\end{array}
$$

\footnotetext{
${ }^{8}$ Technically, the number of items chosen must be an integer, so $n_{i}$ should be restricted to the set of positive whole numbers, but we simplify by assuming that $n$ is a continuous variable. As $n$ becomes larger than a few items, this distinction is trivial.
} 
To ensure that each collection has some positive value to consumers, we require:

$$
\frac{\partial V\left(0, N_{2}\right)}{\partial n_{1}}>0 \quad \frac{\partial V\left(N_{1}, 0\right)}{\partial n_{2}}>0
$$

Furthermore, we restrict attention to substitute goods: ${ }^{9}$

$$
\frac{\partial^{2} V\left(n_{1}, n_{2}\right)}{\partial n_{1} \partial n_{2}} \leq 0
$$

This implies that for all positive $n_{i}$ 's:

$$
V\left(n_{1}, 0\right)+V\left(0, n_{2}\right)>V\left(n_{1}, n_{2}\right) .
$$

The two firms set price schedules $P_{1}\left(n_{1}\right)$ and $P_{2}\left(n_{2}\right)$. If firm $i$ sells by the item, $P_{i}\left(n_{i}\right)=p_{i} n_{i}$, a linear function. If firm $i$ sells only bundles, $P_{i}\left(n_{i}\right)=P_{i}$, the bundle price (the consumer receives all $N_{i}$ items even if she wishes to read only $n_{i}$ of them). Given price schedules, a consumer chooses the number of items he actually reads from each bundle, $n_{1}$ and $n_{2}$, to maximize his surplus net of the cost, $C$, of acquiring those items:

$$
\max _{n_{1}, n_{2}} V\left(n_{1}, n_{2}\right)-C\left(n_{1}, n_{2}\right)
$$

where $C(\cdot)$ is the cost to the consumer of purchasing the combination $\left(n_{1}, n_{2}\right)$.

If each firm sells its entire collection as a bundle:

$$
C\left(n_{1}, n_{2}\right)=d_{1} P_{1}+d_{2} P_{2}
$$

\footnotetext{
${ }^{9}$ Information may partially overlap between items offered by different firms, for example in different but related stories about a single news event. More generally, even substantively unrelated items compete for scarce reader attention. Time spent reading item $a$ cannot be used to read item $b$, reducing the net value of $b$ if one has already obtained $a$. Of course, there might exist complementarities, but the impact of these is beyond our scope. See Van Alstyne and Parker (2000) and Matutes and Regibeau (1992) for models with two complementary information goods.
} 
where $d_{i}=1$ if $n_{i}>0$ and 0 otherwise. If collection 1 is bundled and collection 2 is sold on per item basis:

$$
C\left(n_{1}, n_{2}\right)=d_{1} P_{1}+n_{2} p_{2} .
$$

If both firms charge on a per item basis, then:

$$
C\left(n_{1}, n_{2}\right)=n_{1} p_{1}+n_{2} p_{2} .
$$

\subsection{Pricing Game}

We start to solve the model by first taking as given each firm's decision whether to bundle or sell items individually. Firms compete by simultaneously choosing prices. We derive the pure strategy Bertrand equilibria for the different combinations of bundling strategy. A pair of prices is a Bertrand equilibrium if neither firm could increase its profit by unilaterally changing its prices assuming the other firm does not change its price.

\subsubsection{Both Firms Bundle}

Firm $i$ sells its bundled collection at price $P_{i}$. Since consumers are stochastically identical, firm $i$ 's profit will be $P_{i}$ if the bundle is purchased, else zero. In equilibrium each firm must sell its content, or, the non-selling firm could do strictly better by lowering its price until consumers are willing to purchase its bundle. Consequently, each firm charges the highest $P_{i}$ that induces consumers to purchase its bundle.

The relevant margin is for the consumer choice between purchasing only one bun- 
dle and purchasing both. ${ }^{10}$

$$
\begin{aligned}
V_{B} & \equiv V\left(N_{1}, N_{2}\right) \\
V_{1} & \equiv V\left(N_{1}, 0\right) \\
V_{2} & \equiv V\left(0, N_{2}\right)
\end{aligned}
$$

The consumer's surpluses for these consumption options are given by:

$$
\begin{aligned}
C S_{B} & =V_{B}-P_{1}-P_{2} \\
C S_{1} & =V_{1}-P_{1} \\
C S_{2} & =V_{2}-P_{2}
\end{aligned}
$$

The optimal consumer decisions are shown in Figure 1.

\section{Figure 1: Consumer's Decision When Both Firms Bundle}

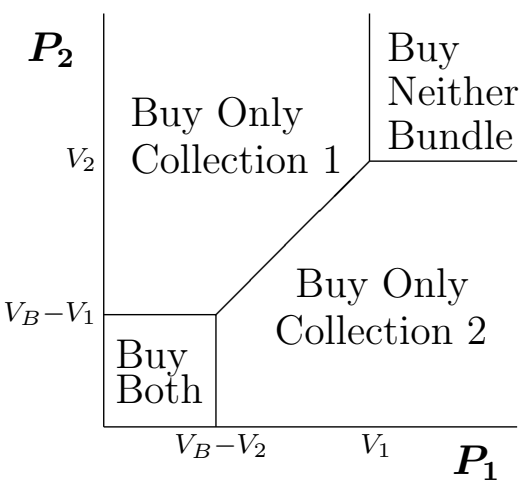

The unique equilibrium prices are:

$$
P_{1}^{B}=V_{B}-V_{2} \quad P_{2}^{B}=V_{B}-V_{1}
$$

\footnotetext{
${ }^{10}$ Since we consider only substitutes, not complements, the choice between buying neither bundle and buying both is not relevant to the firm's decision. Suppose a consumer wishes to purchase neither bundle at current prices. If firm 1 lowers $P_{i}$ a little the consumer may decide to purchase bundle $N_{1}$. However, since the items in $N_{1}$ and $N_{2}$ are substitutes, the consumer will now value $N_{2}$ less, and thus will not choose to purchase both bundles.
} 
where the superscript designates the other firm's strategy. Each consumer purchases both collections so profit to firm $i$ equals $P_{i}^{B}$. Neither firm has an incentive to unilaterally deviate from these prices. Suppose firm 1 chooses $P_{1}^{B}-\epsilon$. Then, all consumers still buy his collection but now at a lower price, and thus a lower profit. If firm 1 raises its price to $P_{1}^{B}+\epsilon$, then $C S_{2}>C S_{B} \cdot{ }^{11}$

\subsubsection{One firm bundles, the other unbundles}

Suppose firm 1 sells its collection as a bundle and firm 2 sells items separately. There is no pure strategy Bertrand equilibrium except for an uninteresting extreme case.

If buying separate items from firm 2, a consumer will choose $n_{2}$ such that the marginal value of an additional item is just equal to $p_{2}$. Let the number of items a consumer purchases from firm 2 at per item price $p_{2}$ be $n_{2}\left(p_{1}, p_{2}\right)$ where $p_{1}$ indicates the marginal price to the consumer for an item from collection 1. So, quantity consumed from firm 2 will be $n_{2}\left(0, p_{2}\right)$ if she also purchases firm 1 's bundle and $n_{2}\left(P_{1}, p_{2}\right)$ is she doesn't purchase firm 1's bundle. ${ }^{12}$ Any candidate equilibria must induce the consumer to purchase items from both firms since from (3) a firm can do strictly better than earning zero profit.

Begin with firm 1's decision. Firm 1 earns profit of $P_{1}$ if consumers buy its bundle, or zero otherwise. Thus, firm 1 wants to price just low enough so that the bundle will be purchased, taking $p_{2}$ as given. Let $P_{1}^{I *}$ be the price that makes the consumer indifferent between buying both the bundle and some separate items versus only

\footnotetext{
${ }^{11}$ Using the surplus definitions in (6)-(8) and substituting the equilibrium prices in (9), we have $C S_{2}=V_{2}-P_{2}=V_{1}-\left(V_{B}-V_{2}\right)$ and $C S_{B}=V_{B}-P_{1}-P_{2}=V_{1}-P_{1}=V_{1}-\left(V_{B}-V_{2}+\epsilon\right)<C S_{2}$. Consumers would only buy firm 2's bundle, reducing firm 1's profit to zero.

${ }^{12}$ Recall that when a consumer purchases a bundle, all items from collection 1 are available at no additional cost.
} 
purchasing separate items; that is, so that $C S^{B I}=C S^{0 I}$. From this condition, we obtain firm 1's profit-maximizing price:

$$
P_{1}^{I *}\left(p_{2}\right)=V\left(N_{1}, n_{2}\left(p_{2}, N_{1}\right)\right)-V\left(0, n_{2}\left(p_{2}, 0\right)\right)+p_{2}\left[n_{2}\left(P_{1}, p_{2}\right)-n_{2}\left(0, p_{2}\right)\right]
$$

Now, turn to firm 2's decision. Given firm 1's bundle is purchased, firm 2's profit is:

$$
\Pi_{2}^{B A}\left(p_{2}\right)=p_{2} n_{2}\left(0, p_{2}\right)
$$

We can show that this cannot be the optimum choice of $p_{2}$ if $n_{2}\left(0, p_{2}\right)<N_{2}$. Since, from (5), items are imperfect substitutes:

$$
n_{2}\left(0, p_{2}\right)<n_{2}\left(P_{1}, p_{2}\right)
$$

Since $P_{1}$ was set to make the consumer just indifferent about buying firm 1's bundle, we know that by slightly reducing $p_{2}$ firm 2 can obtain a discrete jump in item sales by inducing consumers to forego firm 1's bundle. Thus, firm 2's profit increases to:

$$
\Pi_{2}^{0 A}\left(p_{2}\right)=\left(p_{2}-\epsilon\right) n_{2}\left(P_{1}, p_{2}\right)
$$

Firm 1 wants to lower its price just enough to prevent consumers from buying only from firm 2; firm 2 wants to lower its price enough to become the sole provider.

One candidate pure strategy equilibrium remains. Define $\hat{p_{2}}$ such that $n_{2}\left(0, \hat{p_{2}}\right)=$ $N_{2}$. A slight reduction in $p_{2}$ will no longer result in a jump in item sales. Let $p_{2}^{*}$ be the price that maximizes firm 2's profit given that firm 1's bundle is also consumed:

$$
p_{2}^{*}=\operatorname{argmax} p_{2} \max \left[n_{2}\left(0, p_{2}\right), N_{2}\right]
$$

There is a pure strategy equilibrium with prices $P_{1}^{I *}\left(\hat{p_{2}}\right)$ and $\hat{p_{2}}$ only if $\hat{p_{2}}=p_{2}^{*}$. This is a corner solution in which firm 2 maximizes profit at a price such that consumers purchase every item in its collection. This case is somewhat uninteresting because 
all content is inframarginal. In general, one would expect firm 2 to produce some content that was marginal in value. If $p_{2}^{*}<\hat{p_{2}}$ (which we expect to be the general case), then no pure strategy equilibrium exists. At $p_{2}^{*}$, firm 1 would choose $P_{1}^{I *}\left(p_{2}^{*}\right)$ to extract all remaining consumer surplus. But, then a slight reduction in $p_{2}$ would cause a discrete jump in sales and thus higher profit for firm 2.

\subsubsection{Both firms sell unbundled items}

Suppose both firms only offer unbundled items. At prices $p_{1}$ and $p_{2}$, a consumer's demands are $n_{1}\left(p_{1}, p_{2}\right)$ and $n_{2}\left(p_{1}, p_{2}\right)$. Consumers choose $n_{i}$ such that the marginal value of an additional item from collection $i$ equals $p_{i}$. The concavity assumption in (1) and (2) implies that $\frac{\partial n_{i}\left(p_{1}, p_{2}\right)}{\partial p_{i}} \leq 0$ and (4) implies $\frac{\partial n_{i}\left(p_{1}, p_{2}\right)}{\partial p_{j}} \geq 0$ for $i \neq j$. Profit to firm $i$ is $p_{i} n_{i}\left(p_{1}, p_{2}\right)$. A Bertrand Nash equilibrium is found by solving the simultaneous equations:

$$
\begin{aligned}
& \frac{d \Pi_{1}}{d p_{1}}=0 \\
& \frac{d \Pi_{2}}{d p_{2}}=0
\end{aligned}
$$

Let $p_{1}^{I}$ and $p_{2}^{I}$ be the prices that solve these equations. The profit to each firm in this pure strategy Nash equilibrium is:

$$
\Pi_{i}^{I I}=p_{i}^{I} n_{i}\left(p_{1}^{I}, p_{2}^{I}\right)
$$

\subsection{The Bundling Decision}

We now turn to the solution of the complete game, in which firms simultaneously choose whether to bundle in addition to setting price. We characterize the firstbest solution for a firm that chooses a price schedule, $P_{i}\left(n_{i}\right)$, given the other firm's 
pricing choice. ${ }^{13}$ Then, we show that bundling attains this first-best solution whereas unbundling does not.

\section{The first-best solution}

Firm 1 chooses a price schedule, $P_{1}\left(n_{1}\right)$, to maximize its profits given firm 2's price schedule. $P_{1}(0)$ must equal zero because consumer participation is voluntary. Since marginal cost is zero and the consumer population is normalized to one, if $n_{1}^{e}$ items are purchased in equilibrium, firm 1's profit equals $P_{1}\left(n_{1}^{e}\right)$. Given firm 2's price schedule, let $n_{2}\left(n_{1}\right)$ be the number of items from collection 2 a consumer chooses to purchase if $n_{1}$ items from collection 1 are also consumed. Note that $n_{2}\left(n_{1}^{L}\right) \geq n_{2}\left(n_{1}^{H}\right)$ if $n_{1}^{L}<n_{2}^{H}$ since the goods are substitutes.

For a consumer to purchase $n_{1}^{e}$ items from firm 1, this choice must yield at least as much surplus as choosing 0 items. So, with a bit of rearrangement:

$$
P_{1}\left(n_{1}^{e}\right) \leq V\left(n_{1}^{e}, n_{2}\left(n_{1}^{e}\right)\right)-P_{2}\left(n_{2}\left(n_{1}^{e}\right)\right)-\left[V\left(0, n_{2}(0)\right)-P_{2}\left(n_{2}(0)\right)\right]
$$

Firm 1's profits are $P_{1}\left(n_{1}^{e}\right)$. Thus, profits are maximized when this condition is satisfied with a strict equality so that the firm is extracting the entire residual surplus:

$$
P_{1}\left(n_{1}^{e}\right)=V\left(n_{1}^{e}, n_{2}\left(n_{1}^{e}\right)\right)-P_{2}\left(n_{2}\left(n_{1}^{e}\right)\right)-\left[V\left(0, n_{2}(0)\right)-P_{2}\left(n_{2}(0)\right)\right]
$$

Equation (10) identifies the first-best price given any $n_{1}^{e}$. We now turn to the optimum choice of $n_{1}^{e}$. Suppose that (1) holds with a strict inequality for all $n_{1} \leq N_{1}$ so that all items in collection 1 are valued by the consumer. ${ }^{14}$ Then, taking a derivative

\footnotetext{
${ }^{13}$ Bundling and unbundling are each subcases of this general price schedule. For bundling, $P_{i}\left(n_{i}\right)=$ $P_{i}$ if $n_{i}>0$, else zero. For unbundling, $P_{i}\left(n_{i}\right)=p_{i} n_{i}$.

${ }^{14}$ The results can easily be modified if this restriction is relaxed. Suppose, $\frac{\partial V\left(n_{1}, n_{2}\left(n_{1}\right)\right)}{\partial n_{1}}>0$ only for $n_{1} \leq \hat{N}_{1}$ where $\hat{N}_{1}<N_{1}$. The first-best solution has $\hat{N}_{1} \leq n_{1}^{e} \leq N_{1}$ instead of condition (11). The two propositions that follow will still be valid.
} 
of (10) and applying the envelope theorem, $\frac{\partial P_{1}\left(n_{1}^{e}\right)}{\partial n_{1}^{e}}>0$ for all $n_{1}<N_{1}$. Firm 1 can offer at most $N_{1}$ items in equilibrium. The first-best solution is to offer all of these items since all have some value to the consumer:

$$
n_{1}^{e}=N_{1}
$$

Conditions (10) and (11) characterize the first-best solution. We are now ready to prove our two main results:

Proposition 1 Bundling achieves the first-best solution to a firm's profit-maximization problem.

Proof: With a bundle price, a consumer gets access to all items at a flat rate so condition (11) is met. Then, given the other firm's price schedule, a firm can choose its bundle price in order to satisfy (10): $P_{1}=V\left(N_{1}, n_{2}\left(N_{1}\right)\right)-P_{2}\left(n_{2}\left(N_{1}\right)\right)-$ $\left[V\left(0, n_{2}(0)\right)-P_{2}\left(n_{2}(0)\right)\right] .{ }^{15}$ Q.E.D.

Proposition 2 Unbundling yields less profit than the first-best solution.

Proof: Suppose firm 1 sets a linear price of $p_{1}$ and $n_{1}^{e}$ items are purchased in equilibrium. Profit is $p_{1} n_{1}^{e}$. Furthermore, $n_{1}^{e}$ is chosen by the consumer such that $\frac{\partial V\left(n_{1}^{e}, n_{2}\left(n_{1}^{e}\right)\right)}{\partial n_{1}}=p_{1}$. Profit at the first-best solution is given in (10) with $n_{1}^{e}=N_{1}$. Calculating the difference in profit between the first-best solution and linear pricing yields: $V\left(N_{1}, n_{2}\left(N_{1}\right)\right)-P_{2}\left(n_{2}\left(N_{1}\right)\right)-\left[V\left(0, n_{2}(0)\right)-P_{2}\left(n_{2}(0)\right)\right]-\frac{\partial V\left(n_{1}^{e}, n_{2}\left(n_{1}^{e}\right)\right)}{\partial n_{1}} n_{1}^{e}$. Rearranging this difference:

$$
\left[V\left(N_{1}, n_{2}\left(N_{1}\right)\right)-V\left(0, n_{2}(0)\right)-\frac{\partial V\left(n_{1}^{e}, n_{2}\left(n_{1}^{e}\right)\right)}{\partial n_{1}} n_{1}^{e}\right]+\left[P_{2}\left(n_{2}(0)\right)-P_{2}\left(n_{2}\left(N_{1}\right)\right)\right]
$$

\footnotetext{
${ }^{15}$ Note, the price equilibrium when both firms bundle is given by (9). Substituting these prices into the (10) yields: $V_{B}-V_{2}=V_{B}-\left(V_{B}-V_{1}\right)-\left[V_{2}-\left(V_{B}-V_{1}\right)\right]$. This identity does indeed hold.
} 
The term in the second pair of brackets is non-negative since $n_{2}(0) \geq n_{2}\left(N_{1}\right)$. The first bracketed term is positive. This can be seen by noting that $V\left(N_{1}, n_{2}\left(N_{1}\right)\right)$ $V\left(0, n_{2}(0)\right)=\int_{n_{1}=0}^{N_{1}} \frac{\partial V\left(n_{1}, n_{2}\left(n_{1}\right)\right)}{\partial n_{1}} d n_{1}$. Also note that $n_{1}^{e} \leq N_{1}$. The sum of the marginal value of all items from collection $1\left(\int_{n_{1}=0}^{N_{1}} \frac{\partial V\left(n_{1}, n_{2}\left(n_{1}\right)\right)}{\partial n_{1}} d n_{1}\right)$ must exceed the sum of a truncated set of items all of which are weighted at the value of the least best item in that set $\left(\frac{\partial V\left(n_{1}^{e}, n_{2}\left(n_{1}^{e}\right)\right)}{\partial n_{1}} n_{1}^{e}\right)$. Thus, the first-best profit exceeds the profits from linear pricing. Q.E.D.

The intuition for these results is informative. Item sales do not extract their entire marginal value. The item price equals the marginal value of the last item consumed by the reader. All previous items have higher marginal values but the firm only receives the value of the least preferred item that is read. Furthermore, not all items of positive value are necessarily purchased by the consumer when sales are made on a per-item basis. This is inefficient (and unprofitable) since the cost of producing additional copies is zero. Bundling encourages a higher level of consumption. And, bundling enables the firm to capture the full residual value of each unit of content. This logic, taking firm 2's behavior as given, is identical to the argument for the superiority of a two-part tariff over a linear price for a monopolist in Oi (1971).

\subsection{Endogenous Product Creation}

Although digital information goods have negligible marginal costs of reproduction and distribution, there may be significant sunk (first-copy) creation costs. If competition significantly reduces operating profits, investment in new information products may be low. We examine the impact of competition on new product creation in this subsection. 
Consider the following two-stage game with no discounting. Let $F_{i}$ be the sunk costs incurred by firm $i$ in order to create $N_{i}$ items, with $N_{i}$ fixed exogenously ( $i$ $=1,2) \cdot{ }^{16}$ In the first stage, the duopolists simultaneously decide whether to invest to create content. In the second stage, the firms set prices on their bundles. If both firms invest, then the Bertrand equilibrium in which both firms bundle their collections $\left(P_{1}^{B}, P_{2}^{B}\right)$ will obtain. If only one firm invests, that firm will charge the monopoly price $\left(V_{i}\right)$ in the second period. The figure below presents the normal form of this game:

\section{Firm 2}

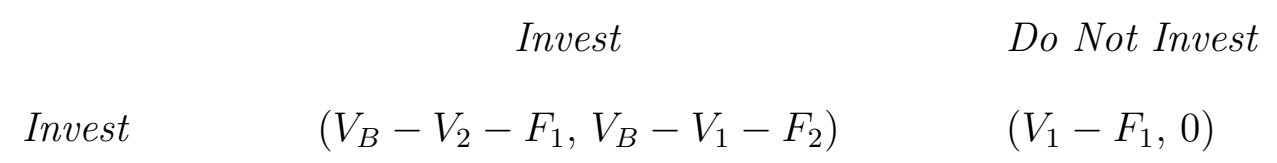

\section{Firm 1}
Do Not Invest
$\left(0, V_{2}-F_{2}\right)$
$(0,0)$

\section{Payoffs $=$ (Firm 1's net profit, Firm 2's net profit)}

We prove two results:

Proposition 3 If it is socially efficient for both firms to invest, then invest is the dominant strategy for both firms.

Proof: By assumption (invest, invest) is the social optimum, so $V_{B}-F_{1}-F_{2}=$ $\max \left\{V_{B}-F_{1}-F_{2}, V_{1}-F_{1}, V_{2}-F_{2}, 0\right\}$. Combining the implied inequalities with the assumption that $V_{B}<V_{1}+V_{2}$ (Eq. 5) yields $V_{B}-V_{2}-F_{1}>0$ and $V_{1}-F_{1}>0$ so

\footnotetext{
${ }^{16}$ In section 5 we determine $N_{i}$ endogenously. We show that duopolists choose an inefficiently small collection.
} 
(invest, $\cdot$ ) is the dominant strategy for firm 1, and likewise for firm 2 by symmetry. Q.E.D.

Proposition 4 If $V_{i}<F_{i}$ (it is not efficient for firm $i$ to invest even if were the sole source of items), then firm $j$ will invest if and only if it is efficient to do so $\left(V_{j} \geq F_{j}\right)$.

Proof: By assumption $V_{i}<F_{i}$, which together with (5) implies that $V_{B}-V_{k}-F_{i}<$ 0. Therefore, firm $i$ 's dominant strategy is to not invest. Knowing that it will be the sole provider if it invests, firm $k$ will invest if and only if $V_{k}-F_{k} \geq 0$. Q.E.D.

There is a third possibility: that both firms want to invest if the other does not, but not if the other does. In this case, $V_{i}>F_{i}$ but $V_{B}-V_{k}<F_{i}(i \neq k)$. There are two Nash equilibria, (invest, do not invest) and (do not invest, invest). One is the social optimum, but in the other the wrong firm invests in content creation.

The latter, inefficient equilibrium is closely related to the problem of "excess inertia" in the network externalities literature (see Farrell and Saloner 1986). In that problem, a first mover gains control of a standard, and the positive network externalities mean that the market cannot support both standards or systems, so the second is not produced even though it would be socially preferred to have the new standard replace the old.

\subsection{Comparing Market Structures}

We have shown that when consumers have stochastically identical demand for content, the only pure strategy equilibrium of the complete game is for both firms to bundle their collections. This equilibrium outcome is efficient. Each consumer has access to all items, so the total value created by item consumption is $V_{B}$. 
If a monopolist controlled all content, she would set a price $P_{M}=V_{B}$ to extract all consumer surplus. Although this too is an efficient allocation, the distribution of surplus among the market participants is much different for these two market structures. From (5) and (9) one can see that the total duopoly profit is less than the monopoly profit $\left(V_{B}+V_{B}-V_{1}-V_{2}<V_{B}\right)$. Thus, some surplus is retained by consumers $\left(V_{1}+V_{2}-V_{B}\right)$ when there is a duopoly.

Finally, even though profits are reduced, duopolists maintain an efficient incentive to invest in content, at least in the situation in which the size of a collection is given exogenously.

\section{Heterogeneous Consumers}

Salinger (1995) showed that bundling could be advantageous when it permits the firm to smooth demand for multiple units. This can be thought of as the operation of the law of large numbers: if buyer valuations are drawn from the same distribution, then average valuation will tend to converge to the distribution mean as the number of items increases, and the firm can extract more of the surplus by bundling and setting the price to $N$ times the mean. This value averaging effect is the main result in Bakos and Brynjolfsson (1998) as well. Of course this effect is most pronounced when consumer valuations are distributionally identical. If consumer preferences are truly heterogeneous, then bundling as an averaging device will not be as effective, and as shown by Chuang and Sirbu (1998) may even be dominated by per item selling.

Therefore, in this section we analyze competition between two information good producers when consumer preferences are heterogeneous. We also compare the performance of the duopoly to a monopoly market. 
We need to impose some structure on preferences across individual consumers. Assume that a consumer who reads $n_{1}$ items from collection 1 and $n_{2}$ items from collection 2 will value her $j$ th best item from collection $i$ at: ${ }^{17}$

$$
w\left(n_{i}^{j}\right)=w_{o}\left(1-\frac{n_{i}^{j}}{k N_{i}}\right) \frac{k\left(N_{1}+N_{2}\right)-n_{1}-n_{2}}{k\left(N_{1}+N_{2}\right)}
$$

in which $w_{o}$ is the value of the consumer's best item, and $k$ is the percent of items that would have positive value to the consumer if it were the only item available. ${ }^{18}$ This formulation extends Chuang and Sirbu (1998). Consumers rank the items in the collection, with a higher $n$ representing a less valuable item.

The last term of (12) is our innovation. As one consumes a greater number of items $\left(n_{i}\right.$ rises), each available item is less valuable to the consumer (versus the value that item would have had if fewer items had been consumed). This implies that items are imperfect substitutes.

The total value of consuming the $n_{1}$ best items from collection 1 and the $n_{2}$ best items from collection 2 is given by:

$$
\begin{aligned}
V\left(n_{1}, n_{2}\right) & =\int_{n=0}^{n_{1}} w_{o}\left(1-\frac{n}{k N_{1}}\right) \frac{k N_{t o t}-n_{t o t}}{k N_{t o t}} d n+\int_{n=0}^{n_{2}} w_{o}\left(1-\frac{n}{k N_{2}}\right) \frac{k N_{t o t}-n_{t o t}}{k N_{t o t}} d n \\
& =w_{o}\left(n_{1}-\frac{\left(n_{1}\right)^{2}}{2 k N_{1}}+n_{2}-\frac{\left(n_{2}\right)^{2}}{2 k N_{2}}\right) \frac{k N_{t o t}-n_{t o t}}{k N_{t o t}}
\end{aligned}
$$

where $N_{t o t}=N_{1}+N_{2}$ and $n_{t o t}=n_{1}+n_{2}$. Given prices for each collection $\left(P_{1}\left(n_{1}\right)\right.$, $\left.P_{2}\left(n_{2}\right)\right)$, consumers choose $n_{1}$ and $n_{2}$ to maximize their surplus net of the cost of acquiring those items.

We have not been able to solve analytically for Nash strategies in this game for a fully general distribution of heterogeneous consumer preferences. Therefore

\footnotetext{
${ }^{17}$ For notational convenience, superscripts for consumers on $w_{o}$ and $k$ have been omitted.

${ }^{18} k$ may be quite small. A given consumer likely will only be interested in a small fraction of the information goods available.
} 
Figure 2: Preference heterogeneity in two dimensions

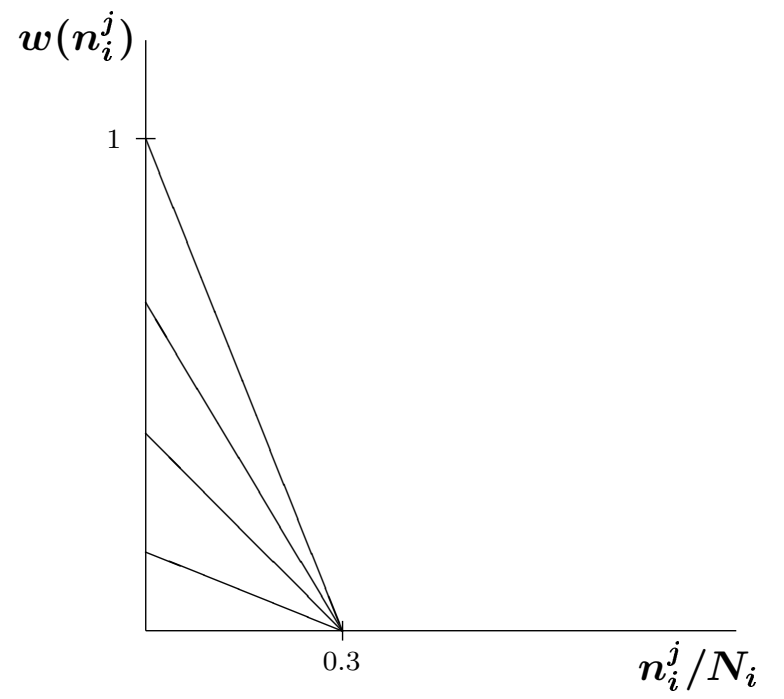

Heterogeneous value intensity $\left(w_{o}\right)$

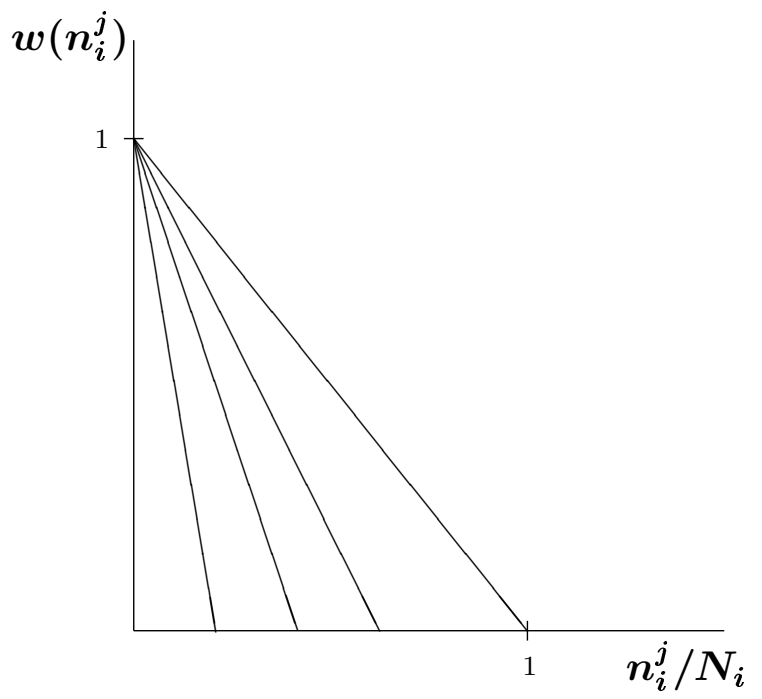

Heterogeneous value breadth $(k)$

we employ numerical simulation methods to analyze the markets. We consider two environments. In the first we allow value intensity to vary, but fix the percentage of items that each consumer values: $w_{o}$ is distributed uniformly on $[0,1]$ and $k=0.3$. In the second environment we fix intensity $\left(w_{o}=1\right)$ and vary breadth $(k \sim U[0,1])$. Notice that both sources of heterogeneity lead to variation in the slope of a consumer's valuations of items rank ordered according to her preferences (see Figure 2).

In Table 1 we present as a benchmark the socially optimal outcomes for a single firm that has 1000 items to sell, and the monopoly outcomes for bundling these items, selling them separately, or offering a mixed bundle (consumer chooses between a bundle or separate items). In this and the subsequent tables, $P_{i}$ is the bundle price charged by firm $i, p_{i}$ is the unit price set by firm $i$ if it sells individual items, and $\Pi_{i}$ is the profit received by firm $i . C S$ is the value of consumers' surplus. Welfare is consumers' surplus plus total profits. $Q_{B}$ represents the number of consumers 
Table 1: Monopoly owns the entire collection

$$
N=1000, k=.3, w_{o} \sim U[0,1]
$$

\begin{tabular}{|c|c|c|c|c|c|c|c|c|}
\hline \multicolumn{9}{|c|}{$N=1000, k=.3, w_{o} \sim U[0,1]$} \\
\hline $\begin{array}{l}\text { Description } \\
\text { Social Optimum }\end{array}$ & $\mathbf{P}_{m}$ & $\mathbf{p}_{m}$ & $\begin{array}{l}\mathbf{Q}_{B} \\
1.0\end{array}$ & $\begin{array}{c}\mathbf{Q}_{I} \\
126.8\end{array}$ & Profit & CS & $\begin{array}{c}\text { Welfare } \\
28.9\end{array}$ & $\begin{array}{c}\% \text { of } \\
\text { Optimum } \\
100.0\end{array}$ \\
\hline Bundling & 29.1 & & 0.5 & & 14.5 & 7.12 & 21.6 & 74.7 \\
\hline Unbundling & & 0.27 & & 42.4 & 11.4 & 8.95 & 20.4 & 70.6 \\
\hline Mixed Bundling & 29.1 & $\geq .51$ & 0.5 & 0.0 & 14.5 & 7.12 & 21.6 & 74.7 \\
\hline \multicolumn{9}{|c|}{$N=1000, w_{o}=1, k \sim U[0,1]$} \\
\hline Social Optimum & & & 1 & 211.3 & & & 96.2 & 100.0 \\
\hline Bundling & 96.2 & & 0.5 & & 48.1 & 24.1 & 72.2 & 75.0 \\
\hline Unbundling & & 0.47 & & 98.0 & 46.1 & 25.0 & 71.1 & 73.7 \\
\hline Mixed Bundling & 112.4 & 0.66 & 0.35 & 25.6 & 56.1 & 20.5 & 76.6 & 79.6 \\
\hline
\end{tabular}

who purchase the bundle. $Q_{I}$ represents the number of items that are purchased separately. ${ }^{19}$

In Tables 2-4 we present outcomes when 1000 items are sold from two separate collections. We calculate the Bertrand equilibria (when they exist) and Stackleberg equilibria for two firms that follow one of our three strategy pairs: both bundle; both sell separate items; or one bundles and the other sells items. We also present the monopoly outcome for a single firm that sells items from two collections following the same strategy pairs for collections as in the corresponding oligopoly cases (e.g., a monopolist selling the two collections as separate sub-bundles versus two firms that each bundle their own collection). We also report the socially optimal outcome for each pricing structure. To further explore market structure effects, we calculate outcomes for several different ratios of collection size.

\footnotetext{
${ }^{19}$ At the social optimum, each consumer has access to all articles that are positively valued. For the first consumer population, this is an average of 126.8 articles; for the second set of consumers, this average is 211.3 articles.
} 


\subsection{Monopoly}

We report in Table 1 the profit-maximizing results for a monopolist who follows one of three strategies to sell 1000 items. The top panel is for a consumer population heterogeneous in value intensity; the bottom panel is for heterogeneity in value breadth.

In Tables 2, 3 and 4 we report the outcomes for a monopolist selling sub-collections rather than all content together. Evidently the monopolist should not sub-bundle. Bundling and mixed bundling monopoly profits are higher when the collection is priced as a whole $(N=1000)$ rather than separated into parts $\left(N_{1}=N_{2}=500\right.$ or $\left.N_{1}=400, N_{2}=600\right)$. There is a simple explanation. Individual items are (imperfect) substitutes for each other. By introducing sub-bundles, the monopolist competes with itself. It is important to remember that the inferiority of sub-bundling is shown only in cases with zero marginal cost. It is easy to show that with positive marginal cost sub-bundling can be a superior strategy, as we observe in consumer magazine and scholarly journal publishing, for example.

Another interesting result is that sub-bundling by a monopolist also leads to lower social welfare than mixed bundling. Consider the following simple example: Consumers are stochastically identical and the entire collection is equally divided into two parts. Suppose that the consumers value each 500 -item collection at $\$ 14$, but value the entire 1000 -item collection at $\$ 20$. A monopolist who sold all 1000 items as a bundle would set price at $\$ 20$ and extract the consumer's entire valuation. However, if the monopolist sells two equal-sized sub-bundles, it can no longer extract $\$ 20$. If each collection is priced at $\$ 10$, the consumer will respond by only choosing one of the two collections, earning a net surplus of $\$ 4$ (as opposed to zero surplus if she were to purchase both sub-bundles). Thus, the monopolist would earn only $\$ 10$ in

revenue. The optimal sub-bundle price is then $\$ 14$. Consumers will purchase only one 
sub-bundle and revenues will be $\$ 14$. However, if the monopolist introduced mixed bundling, it could sell some articles from the second collection, thus increasing total consumption and social welfare. Our numerical results suggest that mixed bundling continues to be socially preferred when consumers are heterogeneous.

\subsection{Duopoly}

We report duopoly outcomes for a variety of firm sizes in Tables 2-4. All calculated duopoly equilibria (Bertrand or Stackleberg) are more efficient than their monopoly counterparts. $^{20}$

\subsubsection{Both Firms Bundle}

In Table 2 we report the results when both firms bundle. The most evident feature of this case is that there are no Bertrand equilibria in pure strategies. For any pair of prices $\left(P_{1}, P_{2}\right)$, there will be three categories of consumers: (a) those that will buy both bundles; (b) those that will buy only one bundle; and (c) those that will buy nothing. If firm 2 charges a relatively high price, firm 1 maximizes profits by undercutting firm 2 so that of those in category (b), all choose firm 1 over firm 2. However, if firm 2's price is low enough, firm 1 is better off ignoring those in category (b) and instead switching to a higher price which maximizes profits on sales to consumers in category (a). This results in a discontinuity in each firm's reaction function and thus no equilibrium in pure strategies. ${ }^{21}$ Therefore, we calculate equilibrium results for a market in which one of the firms is a Stackelberg leader.

\footnotetext{
${ }^{20}$ For the Stackleberg results the number in parentheses indicates the firm that leads.

${ }^{21} \mathrm{~A}$ proof of this result is available in an appendix available from the authors upon request. If collection sizes are substantially different, a pure strategy equilibrium can exist since firms target different niches.
} 
Table 2: Duopoly: Both Firms Bundle

\begin{tabular}{|c|c|c|c|c|c|c|c|}
\hline \multicolumn{8}{|c|}{$N_{1}=N_{2}=500, k=.3, w_{o} \sim U[0,1]$} \\
\hline Description & $\mathbf{P}_{1}$ & $\mathbf{P}_{2}$ & $\Pi_{1}$ & $\Pi_{2}$ & CS & Welfare & $\%$ of Optimum \\
\hline Social Optimum & & & & & & 28.9 & 100 \\
\hline Monopoly & $\geq 22.2$ & 22.2 & 0.0 & 11.1 & 5.56 & 16.7 & 57.7 \\
\hline Bertrand & \multicolumn{7}{|c|}{ No pure-strategy equilibrium exists } \\
\hline Stackleberg (1) & 3.62 & 6.65 & 3.33 & 3.33 & 20.4 & 27.1 & 93.8 \\
\hline \multicolumn{8}{|c|}{$N_{1}=400, N_{2}=600, k=.3, w_{o} \sim U[0,1]$} \\
\hline Social Optimum & & & & & & 28.9 & 100.0 \\
\hline Monopoly & $\geq 19.7$ & 24.2 & 0.0 & 12.1 & 6.06 & 18.2 & 62.8 \\
\hline Bertrand & \multicolumn{7}{|c|}{ No pure-strategy equilibrium exists } \\
\hline Stackleberg (1) & 3.8 & 9.1 & 3.44 & 4.6 & 18.4 & 26.5 & 91.6 \\
\hline Stackleberg (2) & 4.7 & 9.1 & 4.07 & 4.66 & 17.6 & 26.4 & 91.2 \\
\hline \multicolumn{8}{|c|}{$N_{1}=N_{2}=500, w_{o}=1, k \sim U[0,1]$} \\
\hline Social Optimum & & & & & & 96.2 & 100.0 \\
\hline Monopoly & $\geq 74.1$ & 74.1 & 0.0 & 37.0 & 18.5 & 55.6 & 57.7 \\
\hline Bertrand & \multicolumn{7}{|c|}{ No pure-strategy equilibrium exists } \\
\hline Stackleberg (1) & 12.1 & 22.2 & 11.1 & 11.1 & 68.1 & 90.2 & 93.8 \\
\hline \multicolumn{8}{|c|}{$N_{1}=400, N_{2}=600, w_{o}=1, k \sim U[0,1]$} \\
\hline Social Optimum & & & & & & 96.2 & 100.0 \\
\hline Monopoly & $\geq 65.8$ & 80.8 & 0.0 & 40.4 & 20.2 & 60.6 & 63.0 \\
\hline Bertrand & \multicolumn{7}{|c|}{ No pure-strategy equilibrium exists } \\
\hline Stackleberg (1) & 12.8 & 30.4 & 11.6 & 15.3 & 61.3 & 88.2 & 91.6 \\
\hline Stackleberg (2) & 15.6 & 30.5 & 13.7 & 15.4 & 58.7 & 87.8 & 91.2 \\
\hline
\end{tabular}


Table 3: Duopoly: Firm 1 bundles, firm 2 sells separate items

\begin{tabular}{|c|c|c|c|c|c|c|c|}
\hline \multicolumn{8}{|c|}{$N_{1}=N_{2}=500, k=.3, w_{o} \sim U[0,1]$} \\
\hline Description & $\mathbf{P}_{1}$ & $\mathbf{p}_{2}$ & $\Pi_{1}$ & $\Pi_{2}$ & CS & Welfare & $\%$ of Optimum \\
\hline Social Optimum & & & & & & 28.9 & 100.0 \\
\hline Monopoly & 17.2 & 0.25 & 8.6 & 3.18 & 8.96 & 20.7 & 71.8 \\
\hline Bertrand & 8.2 & 0.09 & 5.35 & 3.42 & 17.9 & 26.7 & 92.3 \\
\hline Stackleberg (1) & 9.5 & 0.1 & 5.53 & 3.83 & 16.7 & 26.1 & 90.2 \\
\hline Stackleberg (2) & 8.2 & 0.09 & 5.35 & 3.42 & 17.9 & 26.7 & 92.3 \\
\hline \multicolumn{8}{|c|}{$N_{1}=400, N_{2}=600, k=.3, w_{o} \sim U[0,1]$} \\
\hline Social Optimum & & & & & & 28.9 & 100.0 \\
\hline Monopoly & 14.3 & 0.25 & 6.99 & 4.6 & 9.08 & 20.7 & 71.5 \\
\hline Bertrand & 5.9 & 0.09 & 4.24 & 3.93 & 18.8 & 27.0 & 93.3 \\
\hline Stackleberg (1) & 5.2 & 0.14 & 4.51 & 3.66 & 17.7 & 25.9 & 89.7 \\
\hline Stackleberg (2) & 7.92 & 0.15 & 5.96 & 3.97 & 15.4 & 25.3 & 87.6 \\
\hline \multicolumn{8}{|c|}{$N_{1}=600, N_{2}=400, k=.3, w_{o} \sim U[0,1]$} \\
\hline Social Optimum & & & & & & 28.9 & 100.0 \\
\hline Monopoly & 24.3 & 0.48 & 12.1 & 0.02 & 6.01 & 18.1 & 62.7 \\
\hline Bertrand & 10.8 & 0.09 & 6.59 & 2.87 & 16.8 & 26.2 & 90.8 \\
\hline Stackleberg (1) & 12.4 & 0.1 & 6.75 & 3.23 & 15.5 & 25.5 & 88.3 \\
\hline Stackleberg (2) & 10.8 & 0.09 & 6.59 & 2.87 & 16.8 & 26.2 & 90.8 \\
\hline \multicolumn{8}{|c|}{$N_{1}=N_{2}=500, w_{o}=1, k \sim U[0,1]$} \\
\hline Social Optimum & & & & & & 96.3 & 100.0 \\
\hline Monopoly & 85.1 & 0.66 & 30.6 & 12.5 & 16.3 & 59.4 & 61.6 \\
\hline Bertrand & 36.6 & 0.23 & 18.6 & 14.6 & 51.6 & 84.7 & 88.0 \\
\hline Stackleberg (1) & 36.5 & 0.23 & 18.6 & 14.6 & 51.6 & 84.7 & 87.9 \\
\hline Stackleberg (2) & 40.9 & 0.275 & 20.3 & 15.0 & 46.6 & 81.9 & 85.0 \\
\hline \multicolumn{8}{|c|}{$N_{1}=400, N_{2}=600, w_{o}=1, k \sim U[0,1]$} \\
\hline Social Optimum & & & & & & 96.3 & 100.0 \\
\hline Monopoly & 66.3 & 0.435 & 15.0 & 25.9 & 25.8 & 66.7 & 69.2 \\
\hline Bertrand & 30.8 & 0.25 & 15.3 & 18.9 & 50.5 & 84.6 & 87.8 \\
\hline Stackleberg (1) & 31.1 & 0.255 & 15.4 & 18.9 & 49.9 & 84.2 & 87.4 \\
\hline Stackleberg (2) & 33.0 & 0.285 & 16.4 & 19.2 & 46.9 & 82.4 & 85.6 \\
\hline \multicolumn{8}{|c|}{$N_{1}=600, N_{2}=400, w_{o}=1, k \sim U[0,1]$} \\
\hline Social Optimum & & & & & & 96.3 & 100.0 \\
\hline Monopoly & 90.6 & 0.675 & 35.6 & 9.61 & 17.6 & 62.8 & 65.2 \\
\hline Bertrand & 44.5 & 0.205 & 22.2 & 11.2 & 50.7 & 84.1 & 87.3 \\
\hline Stackleberg (1) & 48.4 & 0.215 & 22.4 & 11.9 & 48.2 & 82.5 & 85.7 \\
\hline Stackleberg (2) & 47.3 & 0.24 & 23.4 & 11.5 & 47.5 & 82.4 & 85.5 \\
\hline
\end{tabular}


In welfare terms, consumers' surplus in the Stackelberg equilibrium with both firms bundling is typically three times higher than for a monopoly (whether it bundles - Table 1 - or sub-bundles as in Table 2). Competition also reduces combined profit to about half the monopoly level. Overall, social welfare tends to be about $40 \%$ higher under duopoly than with a sub-bundling monopoly; the advantage is about 20\% compared to a bundling monopoly (Table 1).

\subsubsection{One firm bundles, one firm sells separate items}

In Table 3 we report duopoly outcomes when only the first firm bundles its collection. A Bertrand equilibrium exists, and is quite similar to both Stackleberg equilibria for a given distribution of collection sizes and consumer types. A striking result is that the bundling firm is at a decided advantage. For example, in the second panel we show that firm 1 obtains higher profits even though firm 2 has the larger collection to sell. Even in the second-to-last panel, in which firm 2 has higher total profit than firm 1, the first firm earns higher per item profit by bundling. These results are consistent with the finding for stochastically identical consumers that bundling offers a competitive advantage over unbundling.

\subsubsection{Both firms sell separate items}

We report in Table 4 the duopoly outcomes when both firms sell separate items. Item prices are substantially lower than with a monopoly. Combined profits do not decline as much as prices, however. Social welfare from a duopoly is about 20-25\% higher than for a monopoly.

When we compare welfare across pricing strategies for a duopoly, we see that bundling is much more efficient than selling content on a per item basis. Consumers 
Table 4: Duopoly: Both Firms Sell Separate Items

\begin{tabular}{|c|c|c|c|c|c|c|c|}
\hline \multicolumn{8}{|c|}{$N_{1}=N_{2}=500, k=.3, w_{o} \sim U[0,1]$} \\
\hline Description & $\mathbf{p}_{1}$ & $\mathbf{p}_{2}$ & $\Pi_{1}$ & $\Pi_{2}$ & CS & Welfare & $\%$ of Optimum \\
\hline Social Optimum & & & & & & 28.9 & 100.0 \\
\hline Monopoly & 0.27 & 0.27 & 5.72 & 5.72 & 8.96 & 20.4 & 70.6 \\
\hline Bertrand & 0.134 & .134 & 4.69 & 4.69 & 16.5 & 25.8 & 89.4 \\
\hline Stackleberg (1) & 0.17 & 0.15 & 4.83 & 5.29 & 14.8 & 24.9 & 86.1 \\
\hline \multicolumn{8}{|c|}{$N_{1}=400, N_{2}=600, k=.3, w_{o} \sim U[0,1]$} \\
\hline Social Optimum & & & & & & 28.9 & 100.0 \\
\hline Monopoly & 0.27 & 0.27 & 4.58 & 6.87 & 8.96 & 20.4 & 70.6 \\
\hline Bertrand & 0.133 & 0.15 & 4.01 & 5.64 & 15.9 & 25.5 & 88.2 \\
\hline Stackleberg (1) & 0.135 & 0.15 & 4.01 & 5.68 & 15.8 & 25.5 & 88.2 \\
\hline Stackleberg (2) & 0.145 & 0.175 & 4.37 & 5.78 & 14.6 & 24.8 & 85.6 \\
\hline \multicolumn{8}{|c|}{$N_{1}=N_{2}=500, w_{o}=1, k \sim U[0,1]$} \\
\hline Social Optimum & & & & & & 96.3 & 100.0 \\
\hline Monopoly & 0.47 & 0.47 & 23.0 & 23.0 & 25.0 & 71.1 & 73.8 \\
\hline Bertrand & 0.296 & 0.296 & 20.1 & 20.1 & 45.3 & 85.6 & 88.8 \\
\hline Stackleberg (1) & 0.32 & 0.305 & 20.3 & 20.9 & 43.1 & 84.4 & 87.6 \\
\hline \multicolumn{8}{|c|}{$N_{1}=400, N_{2}=600, w_{o}=1, k \sim U[0,1]$} \\
\hline Social Optimum & & & & & & 96.3 & 100.0 \\
\hline Monopoly & 0.47 & 0.47 & 18.4 & 27.6 & 25.0 & 71.1 & 73.8 \\
\hline Bertrand & 0.287 & 0.314 & 16.7 & 23.9 & 44.4 & 85.0 & 88.3 \\
\hline Stackleberg (1) & 0.31 & 0.32 & 16.8 & 24.7 & 42.7 & 84.2 & 87.4 \\
\hline Stackleberg (2) & 0.295 & 0.335 & 17.4 & 24.1 & 42.4 & 83.9 & 87.1 \\
\hline
\end{tabular}


retain much of the surplus gain because bundling duopolists fiercely compete. Indeed, in our simulations combined firm profits are lower when both firms bundle. For example, when firms are of equal size, firm 1 is the Stackleberg leader, $k=.3$ for all consumers, $w_{o}$ is uniformly distributed from zero to one, and both firms bundle, each will earn a profit of $\$ 3.33$ (Table 2). However, if both firms sold items separately profits would increase by more than $50 \%$ (to $\$ 4.83$ and $\$ 5.29$ respectively). But switching to item sales cuts consumers' surplus by $\$ 5.69$ (from $\$ 20.44$ to $\$ 14.75$ ). The decrease in consumers' surplus exceeds the total magnitude in gains to firms' profits, so efficiency is higher with bundling.

\subsection{Endogenous Bundling Decisions: Mixed Bundling}

We now consider a game in which firms simultaneously choose a bundle and a per item price and offer both to consumers. This is known as mixed bundling. Pure bundling and pure unbundling are special cases of mixed bundling: choosing an infinite bundle price is equivalent to playing "sell separately" as a pure strategy. Likewise, an infinite item price is equivalent to "bundle." Of course, by choosing intermediate prices, firms can offer a mixture of bundles and separate items to a heterogeneous population, so the strategy space is richer. ${ }^{22}$

Mixed bundling was considered by Chuang and Sirbu (1998) for a monopolist. Not surprisingly, since it nests bundling and item sales, they found that mixed bundling weakly dominated the two pure strategies. We examine profits, prices and welfare when competing firms simultaneously choose their bundling strategy and prices through playing a mixed bundling game. ${ }^{23}$

\footnotetext{
${ }^{22}$ When consumers are stochastically identical mixed bundling is irrelevant because all consumers will make the same choice: either purchase a bundle or purchase separate items (or neither).

${ }^{23}$ We should be clear that mixed bundling is not a mixed strategy in game theoretic terms. Both
} 
Let firm 1 set prices $p_{1}$ and $P_{1}$ at the same time firm 2 sets $p_{2}$ and $P_{2}$. We reported the results for optimal mixed bundling by a monopolist in Table 1 . When value intensity is heterogeneous $\left(w_{o} \sim U[0,1]\right)$ bundling maximizes monopoly profits (see Table 1). Mixed bundling performs the same by mimicking bundling (that is, by setting price to $\$ 0.51$ or higher, no separate items are purchased). However, when value intensity is heterogeneous $(k \sim \mathrm{U}[0,1])$, mixed bundling is strictly more profitable than pure bundling. With value intensity variation, consumers who would not purchase a bundle have relatively low per-item valuations. To get them to purchase any items separately requires a low price. However, if the monopolist did this, highvaluation consumers would buy items separately rather than as an expensive bundle, so the monopolist needs to set a relatively high item price and forego most item sales when offering mixed bundling. With value breadth variation, consumers that value only a few items (and thus are not willing to purchase the bundle) do highly value some of the items in the collection. So, the monopolist can sell some items (at a high price) without giving high- $k$ consumers much incentive to switch away from the bundle option. In this case item sales make up almost $30 \%$ of the total revenue from mixed bundling.

In Table 5 we report the Bertrand equilibria (when they exist) for a variety of relative firm sizes. We introduce heterogeneity in value intensity $\left(w_{o} \sim U[0,1]\right)$ in the top panel, and in the bottom value breadth is heterogeneous.

When firms are of similar size no Bertrand equilibrium exists. This is the case in these simulations because mixed bundling is driven by competition in bundle prices. Selling bundles to consumers is the best way to capture most of the surplus. As a result, when firms offer mixed bundles, the competitive pressure is most intense in the options are offered with probability one to consumers, who may select from the menu. 
setting of bundle prices. However, as we showed in the previous section, an equilibrium does not exist when firms simultaneously choose bundle prices for a heterogeneous population of consumers.

With sufficiently different firm sizes, a Bertrand equilibrium emerges because the firms find it more profitable to target different niches: the small firm sells to consumers who do not wish to purchase the expensive bundle that the larger firm is offering.

In Table 6 we report the equilibrium consumer choices. In columns 1I and 2I we tabulate the population fraction that purchases items individually from firms 1 and 2 , respectively. In columns $1 \mathrm{~B}$ and $2 \mathrm{~B}$ we tabulate the fraction purchasing bundles from firms 1 and 2, respectively. When an equilibrium exists, most revenue is from bundle sales. When value intensity varies $\left(w_{o} \sim U[0,1]\right)$, item sales constitute less

than $.5 \%$ of total revenue. When value breadth varies $[k \sim U[0,1])$ less than $5 \%$ of the smaller firm's revenues come from item sales, though the larger firm can obtain up to $30 \%$ of its revenues from item sales. It appears that bundling is the dominant source of revenue if consumer preferences are heterogeneous, even when firms offer a choice of bundles and individual articles. This is consistent with the experience of most scholarly journals and consumer magazines, for example.

\section{Endogenous Collection Size}

To this point we have primarily focused on static efficiency. Once an information good exists, since the marginal cost of reproduction and distribution is zero, social welfare is maximized by distributing each item to everyone who has a positive value for it. A duopoly competing in price does not achieve this objective completely, but it does greatly outperform a monopolist when consumers have heterogeneous pref- 
Table 5: Bertrand Equilibria for Mixed Bundling

\begin{tabular}{cccccccc}
\multicolumn{8}{c}{$k=.3, w_{o} \sim U[0,1]$} \\
$\mathbf{N}_{\mathbf{1}}$ & $\mathbf{N}_{\mathbf{2}}$ & $\mathbf{P}_{\mathbf{1}}$ & $\mathbf{P}_{\mathbf{2}}$ & $\mathbf{\Pi}_{\mathbf{1}}$ & $\mathbf{\Pi}_{\mathbf{2}}$ & $\mathbf{C S}$ & Welfare \\
500 & 500 & \multicolumn{5}{c}{ No Pure-Strategy Equilibrium Exists } \\
460 & 540 & \multicolumn{5}{c}{ No Pure-Strategy Equilibrium Exists } \\
400 & 600 & $(0.16,4.2)$ & $(0.14,6.6)$ & 2.99 & 4.84 & 19.6 & 27.4 \\
300 & 700 & $(0.18,3.2)$ & $(0.25,11.1)$ & 2.6 & 6.41 & 17.2 & 26.2 \\
200 & 800 & $(0.19,2.3)$ & $(0.32,15.8)$ & 1.72 & 8.62 & 14.7 & 25.0 \\
\hline \multicolumn{7}{c}{$w_{o}=1, k \sim U[0,1]$} \\
500 & 500 & No Pure-Strategy Equilibrium Exists \\
400 & 600 & \multicolumn{5}{c}{ No Pure-Strategy Equilibrium Exists } \\
300 & 700 & No Pure-Strategy Equilibrium Exists \\
200 & 800 & $(0.45,8.0)$ & $(0.49,62.0)$ & 6.64 & 32.9 & 46.1 & 85.7 \\
100 & 900 & $(0.45,4.0)$ & $(0.57,86.0)$ & 3.27 & 43.2 & 34.5 & 81.0
\end{tabular}

Table 6: Consumer Choice and Revenue Mix for Mixed Bundling

\begin{tabular}{|c|c|c|c|c|c|c|c|c|c|}
\hline \multicolumn{10}{|c|}{$k=.3, w_{o} \sim U[0,1]$} \\
\hline & & \multicolumn{4}{|c|}{ Consumer Choices } & \multicolumn{2}{|c|}{ Bundling Revenue (BR) } & \multicolumn{2}{|c|}{ BR as $\%$ of Total Rev. } \\
\hline $\mathbf{N}_{1}$ & $\mathbf{N}_{2}$ & 1I & 1B & $2 \mathrm{I}$ & $2 \mathrm{~B}$ & Firm 1 & Firm 2 & Firm 1 & Firm 2 \\
\hline 400 & 600 & 0.04 & 0.71 & 0.0 & 0.74 & 2.98 & 4.84 & 100.0 & 100.0 \\
\hline 300 & 700 & 0.0 & 0.8 & 0.02 & 0.58 & 2.6 & 6.41 & 100.0 & 100.0 \\
\hline 200 & 800 & 0.0 & 0.74 & 0.01 & 0.55 & 1.72 & 8.62 & 100.0 & 100.0 \\
\hline \multicolumn{10}{|c|}{$w_{o}=1, k \sim U[0,1]$} \\
\hline 200 & 800 & 0.18 & 0.79 & 0.61 & 0.39 & 6.32 & 24.2 & 95.0 & 73.0 \\
\hline 100 & 900 & 0.16 & 0.77 & 0.64 & 0.35 & 3.1 & 30.1 & 95.0 & 70.0 \\
\hline
\end{tabular}


erences. Competing firms bid down prices so consumers access more positive-valued items. However, the full social welfare story is more complicated than this. Information goods have significant first-copy costs. In Section 3.4 we considered the incentive to create a collection when both duopolists bundle a fixed-size collection and sell to a stochastically identical consumer base. In this section we allow firms not only to choose whether to create a collection but also how large it will be. We assume items have convex first-copy costs. We solve a two-stage game for creation followed by selling. First firms simultaneously choose the number of items to create. Then they simultaneously choose prices given the collection sizes. We consider both stochastically identical and heterogeneous consumers, allow for various bundling and unbundling strategies, and compare the duopoly outcomes to the corresponding monopoly outcomes.

Assume the investment cost of producing $N_{i}$ items is given by:

$$
C\left(N_{i}\right)=\alpha N_{i}+\beta\left(N_{i}\right)^{2}
$$

$\alpha$ and $\beta$ are assumed to be positive. ${ }^{24}$ In the first stage firms simultaneously choose $\left(N_{1}, N_{2}\right)$. In the second stage they compete in a pricing game (taking the bundling decision as exogenous). Let $\Pi_{1}\left(N_{1}, N_{2}\right)$ and $\Pi_{2}\left(N_{1}, N_{2}\right)$ be the firms' respective operating profits from this price game. Thus, firm $i$ chooses $N_{i}$ to maximize $\Pi_{i}\left(N_{1}, N_{2}\right)-$ $C\left(N_{i}\right)$ taking $N_{j}$ as given $(i \neq j)$. In Table 7 we provide examples of the resulting Nash equilibria for both stochastically identical and heterogeneous consumers

\footnotetext{
${ }^{24} \beta>0$ implies first-copy costs are convex. If there were constant returns to scale $(\beta=0)$ or economies of scale $(\beta<0)$ then no pure-strategy equilibrium would exist. Larger collections allow firms to extract slightly more revenue per item. With constant marginal costs of production, the optimal number of items will either be zero or infinite. Only with increasing marginal costs will an interior solution exist.
} 
Table 7: Endogenous Collection Size Cost: $\mathbf{C}\left(\mathbf{N}_{\mathbf{i}}\right)=\alpha \mathbf{N}_{\mathbf{i}}+\beta\left(\mathbf{N}_{\mathbf{i}}\right)^{\mathbf{2}}$ Bertrand Outcomes

\begin{tabular}{|c|c|c|c|c|c|c|c|}
\hline$\alpha$ & $\boldsymbol{\beta}$ & Hetero? & Bundle? & $\mathbf{N}_{\mathbf{i}}^{*}$ & Profits & CS & Welfare \\
\hline .006 & .00003 & No & Both & $(492,492)$ & $(2.86,2.86)$ & 30.7 & 36.4 \\
\hline .006 & .00003 & No & Neither & $(282,282)$ & $(2.73,2.73)$ & 15.3 & 20.7 \\
\hline .008 & .00003 & No & Both & $(459,459)$ & $(2.21,2.21)$ & 28.6 & 33.0 \\
\hline .006 & .00005 & No & Both & $(295,295)$ & $(1.72,1.72)$ & 18.4 & 21.8 \\
\hline .006 & .00003 & $k$ & Neither & $(528,528)$ & $(9.73,9.73)$ & 47.8 & 67.2 \\
\hline .008 & .00003 & $k$ & Neither & $(500,500)$ & $(8.64,8.64)$ & 45.2 & 62.5 \\
\hline .006 & .00005 & $k$ & Neither & $(318,318)$ & $(5.84,5.84)$ & 28.7 & 40.4 \\
\hline .006 & .00003 & $k$ & Firm 1 & $(495,448)$ & $(7.76,4.32)$ & 48.5 & 60.6 \\
\hline .006 & .00003 & $w_{o}$ & Firm 1 & $(125,30)$ & $(0.33,0.05)$ & 1.97 & 2.35 \\
\hline \multicolumn{8}{|c|}{ Social Optimum } \\
\hline .006 & .00003 & No & & $(862,862)$ & & & 44.6 \\
\hline .008 & .00003 & No & & $(829,829)$ & & & 41.2 \\
\hline .006 & .00005 & No & & $(517,517)$ & & & 26.7 \\
\hline .006 & .00003 & $k$ & & $(1504,1504)$ & & & 135 \\
\hline .008 & .00003 & $k$ & & $(1470,1470)$ & & & 130 \\
\hline .006 & .00005 & $k$ & & $(902,902)$ & & & 81.4 \\
\hline .006 & .00003 & $w_{o}$ & & $(381,381)$ & & & 8.72 \\
\hline .008 & .00003 & $w_{o}$ & & $(348,348)$ & & & 7.26 \\
\hline \multicolumn{8}{|c|}{ Monopoly Outcomes } \\
\hline .006 & .00003 & $k$ & Neither & $(667,667)$ & $(13.4,13.4)$ & 33.2 & 59.9 \\
\hline .008 & .00003 & $k$ & Neither & $(634,634)$ & $(12.1,12.1)$ & 31.5 & 55.6 \\
\hline .006 & .00005 & $k$ & Neither & $(400,400)$ & $(8.0,8.0)$ & 19.9 & 35.9 \\
\hline .006 & .00003 & $k$ & Collection 1 & $(770,480)$ & $(23.5,1.21)$ & 22.3 & 47.0 \\
\hline .006 & .00003 & $w_{o}$ & Neither & $(91,91)$ & $(0.247,0.247)$ & 1.63 & 2.12 \\
\hline .006 & .00003 & $w_{o}$ & Collection 1 & $(145,45)$ & $(1.02,-.33)$ & 1.24 & 1.93 \\
\hline .008 & .00003 & $w_{o}$ & Neither & $(57,57)$ & $(.1, .1)$ & 1.02 & 1.22 \\
\hline
\end{tabular}

for those bundling strategies that have a pure-strategy Bertrand equilibrium in the pricing game. For comparison, we also present the outcomes which maximize social welfare and monopoly profits. For the monopoly outcome, the firm chooses $N_{1}, N_{2}$, $P_{1}$ and $P_{2}$ in order to maximize its total profit (revenue less investment costs) from the two collections.

When consumers are stochastically identical (the first four lines of Table 7), a duopoly creates too little content. Recall that a bundling monopolist extracts all of consumers' surplus by setting a price of $V_{B}$ for the entire pool of items. As a result, 
the monopolist's objective function is the same as a social welfare maximizer's. With $\alpha=.006, \beta=.0003$, a monopolist would maximize profits and social welfare by creating two bundles each with 862 items and charging a bundle price of $\$ 99.56$ to consumers for access to both collections, which would yield social welfare of $\$ 44.56$. Each duopolist in equilibrium will create only 492 items. Consumers purchase both bundles so there is efficient distribution of the created content. Due to undercreation, however, social welfare is $81.6 \%$ of the maximum (36.4 compared to 44.6$)$. If each firm is selling items separately, welfare is further reduced. Per-item pricing extracts less consumers' surplus than bundling so firms have a lower incentive to create content. As a result each firm creates only 282 items. Furthermore, items that are produced will not be distributed efficiently since consumers face a price of $\$ .30$ on the margin. If a consumer values an item between zero and thirty cents, the item will not be consumed even though it would be efficient to do so since its marginal distribution cost is zero. As a result of these two sources of inefficiency social welfare under per-item pricing reaches only $46 \%$ of the optimum (20.7 compared to 44.6$)$.

With heterogeneous consumers the story is quite different. A duopoly creates less than efficient amount of content since firms are unable to capture all of the surplus from that content. However, the same is now true for the monopolist since consumers differ in their aggregate valuations. Of course, a monopolist captures more surplus than the duopolists, so the monopolist has the greater incentive to invest in content. However, a monopolist charges higher prices which distort the distribution of those items that are produced. The results in Table 7 indicate that this second effect dominates: for corresponding cases the duopoly social welfare is always higher than from a monopoly. With $\alpha=.006$ and $\beta=.00003, w_{o}=1$ for all consumers, value breadth heterogeneous $(k \sim U[0,1])$, the (row 4 ) efficient outcome is to produce 1504 
items in each collection, achieving a social welfare of $\$ 135$. A monopolist who sold items separately would set price at $\$ .47$ and produce 667 items in each collection (row 1 of the monopoly panel). Each duopoly firm would price at $\$ .30$ and produce 528 items (row 5 in the duopoly panel). The duopoly achieves a higher social welfare $(67>60)$.

The same result holds if collection 1 is bundled rather than sold on a per-item basis. There is a greater incentive to produce content for collection 1 since bundling extracts greater surplus than unbundling, especially if $w_{o}$ varies across consumers. Even though a duopoly results in the creation of fewer items (row 8 duopoly vs. row 4 monopoly), they are distributed more efficiently because a monopolist would set much higher prices.

Throughout the paper we have stressed the static welfare gains from more efficient distribution by competing firms. When we consider the dynamic issue of new content creation, the social performance of monopoly improves because it can extract more surplus and thus creates closer to the optimal amount of content. However, with heterogeneous consumer preferences, we find across all of our numerical simulations that the duopoly distribution advantage exceeds the monopoly creation advantage, and thus the duopoly is still preferred on social welfare grounds.

\section{Concluding Remarks}

In this paper we explored the interaction between competition and the bundling of electronically-delivered information goods. Some of the results from the previous monopoly-focused literature hold for a duopoly. For example, when consumers have stochastically identical total valuations for the aggregate collection and there 
are no marginal costs of production for existing information goods, bundling is more profitable than unbundling. However, consumer homogeneity has unreasonable implications for monopoly efficiency and for the distribution of surplus between firms and consumers. One of our main contributions is to focus attention on bundling (monopoly and competitive) with heterogeneous consumers. With diverse preferences, bundling is not guaranteed to be superior to separate item sales. In addition, a duopoly, compared to a monopoly, yields much lower prices and slightly less profit regardless of the bundling strategies employed.

Lower industry profit in a static analysis implies a dynamic concern: lower incentives to create new content. We find that the dynamic implication with stochastically identical consumers is again reassuring (fully efficient creation incentives, even with a duopoly) - but unrealistic. When we study the problem of creation incentives with heterogeneous consumers, we discover a trade-off. A monopoly is likely to produce closer to the efficient amount of content. However, the higher prices on existing content that a monopolist charges lead to efficiency losses in distribution that tend to outweigh the efficiency gains from having more content. As a result, a duopoly is welfare-improving even though it is likely to result in fewer total information goods.

From a strategic perspective we reinforce the emerging view that bundling is a powerful tool. However, it also results in rather fierce competition between firms. Consequently, consumers benefit from competitive bundling. Fierce competition leads to more potential readers having access to the content due to the lower subscription fees. Furthermore, bundling results in efficient consumption decisions since subscribers face no extra fee for accessing additional items.

There are a number of questions left for future work. In our current model, a random item selected from one firm has the same expected value to a given consumer 
as a random item selected from the other firm. In fact, when consumers differ in their tastes, some are more likely to favor items from one firm while others favor another firm. ${ }^{25}$ The degree of competition between firms is weakened, which we might expect would result in higher equilibrium prices and thus greater distribution inefficiency.

We ignored several characteristics of the cost structure for most information goods. Although marginal costs of production are quite low, these costs are still positive. For non-negligible marginal costs, Chuang and Sirbu (1998) show that pure unbundling will be more profitable than pure bundling for a monopolist in the absence of large economies of scale. In addition, we ignored transaction costs. Each time a consumer purchases a product, terms must be negotiated and an exchange of payment for the good must be implemented. These transaction costs are another source of efficiency gain for bundling, which reduces the number of separate transactions. On the other hand, search costs are likely to reduce the incentive to bundle. If a firm offers a large, varied bundle, consumers will have a difficult time locating those items which are most valuable to them. This may induce firms to offer smaller, niche-oriented bundles.

Finally, we would like to explore a richer set of bundling possibilities. Like the previous literature, we have focused on bundling, unbundling, and mixed bundling. With $N$ goods, firms could form up to $2^{N}-1$ bundles and price each individually. Such a model is infeasible to solve for reasonable $N$. However, we would like to understand how competition is affected if firms use more complex bundling and pricing strategies than we have thus far considered.

\footnotetext{
${ }^{25}$ Fay (2001) begins to analyze the effects of such product differences on the distribution of surplus among the market participants.
} 


\section{References}

Adams, W. J. and J. L. Yellen (1976). Commodity bundling and the burden of monopoly. Quarterly Journal of Economics 90, 475-498.

Aron, D. J. and S. S. Wildman (1999). Effecting a price squeeze through bundled pricing. In S. E. Gillett and I. Vogelsang (Eds.), Competition, Regulation and Convergence: Current Trends in Telecommunications Policy Research. Mahwah, New Jersey: Lawrence Erlbaum Associates.

Bakos, Y. and E. Brynjolfsson (1998). Bundling information goods: Pricing, profits and efficiency. In D. Hurley, B.Kahin, and H. Varian (Eds.), The Economics of Digital Information Goods. Cambridge, Massachusetts: MIT Press.

Bakos, Y. and E. Brynjolfsson (1999, April). Bundling and competition on the internet: Aggregation strategies for information goods. Working paper series, MIT Sloan School of Management.

Carbajo, J., D. D. Meza, and D. J. Seidmann (1990). A strategic motivation for commodity bundling. The Journal of Industrial Economics 38(3), 283-298.

Chuang, J. C.-I. and M. A. Sirbu (1998). Network delivery of information goods: Optimal pricing of articles and subscriptions. In D. Hurley, B.Kahin, and H. Varian (Eds.), The Economics of Digital Information Goods. Cambridge, Massachusetts: MIT Press.

Farrell, J., H. K. Monroe, and G. Saloner (1998). The vertical organization of industry: Systems competition versus component competition. Journal of Economics and Management Strategy 7(2), 143-182.

Farrell, J. and G. Saloner (1986, December). Installed base and compatibility: In- 
novation, product preannouncements and predation. American Economic Review 76, 940-55.

Fay, S. A. (2001). Does greater sub-additivity between competing bundles always lead to lower prices. Working Paper.

Fishburn, P. C., A. M. Odlyzko, and R. C. Siders (2000). Fixed fee versus unit pricing for information goods: Competition, equilibria, and price wars. In B. Kahin and H. R. Varian (Eds.), Internet Publishing and Beyond: The Economics of Digital Information and Intellectual Property, pp. 167-189. Cambridge, MA: MIT Press.

Gilpin, K. N. (1997). Concerns about aggressive publishing giant. New York Times. December 27: D2.

Hanson, W. and R. K. Martin (1990). Optimal bundle pricing. Management Science $36,155-174$.

MacKie-Mason, J. K. and J. Riveros (1998). Economics and electronic access to scholarly information. In D. Hurley, B. Kahin, and H. Varian (Eds.), The Economics of Digital Information Goods. Cambridge, Massachusetts: MIT Press.

MacKie-Mason, J. K. and H. R. Varian (1996). Some economics of the internet. In W. Sichel (Ed.), Networks, Infrastructure and the New Task for Regulation. Ann Arbor, Michigan: University of Michigan Press.

Matutes, C. and P. Regibeau (1992). Compatibility and bundling of complementary goods in a duopoly. The Journal of Industrial Economics 40(1), 37-53.

McAfee, R. P., J. McMillan, and M. D. Whinston (1989). Multiproduct monopoly, commodity bundling, and correlation of values. The Quarterly Journal of Economics 114, 371-383. 
Nalebuff, B. J. (1999, November). Bundling. Working Paper, available at http://papers.ssrn.com/paper.taf?abstract_id=185193.

Nalebuff, B. J. (2000, August). Competiting against bundles. Working Paper, available at http://papers.ssrn.com/paper.taf?abstract_id=239684.

Oi, W. Y. (1971, February). A disneyland dilemma: Two-part tariffs for a mickey mouse monopoly. Quarterly-Journal-of-Econ 85(1), 77-96.

Riveros, J. F. (1999). Bundling Information Goods: Theory and Evidence. Ph. D. thesis, University of Michigan, Department of Economics.

Salinger, M. A. (1995). A graphical analysis of bundling. Journal of Business 68, 85-98.

Van Alstyne, M. W. and G. Parker (2000, October). Information complements, substitutes, and strategic product design. Available at http://papers.ssrn.com/paper.taf?ABSTRACT_ID=249585.

Whinston, M. D. (1990). Tying, foreclosure, and exclusion. American Economic Review 80(4), 837-859. 